\title{
Association between the inability to identify particular odors and physical performance, cognitive function, and/or brain atrophy in community-dwelling older adults from the Fukuoka Island City study
}

Yujiro Kose ${ }^{1,2^{*}}$, Yoichi Hatamoto ${ }^{2,3}$, Rie Takae ${ }^{2,4}$, Yuki Tomiga ${ }^{2}$, Jun Yasukata ${ }^{2,5}$, Takaaki Komiyama ${ }^{6}$ and Yasuki Higaki ${ }^{1,2^{*}}$

\begin{abstract}
Background: Olfactory dysfunction is associated with severe brain atrophy and cognitive impairment in Parkinson's disease. However, it remains unknown whether an inability to identify particular odors is associated with physical performance, cognitive function, and/or brain atrophy in community-dwelling older adults.

Methods: In this cross-sectional study, 44 community-dwelling older adults were included (14 males, 30 females; mean age: $72.4 \pm 5.7$ years, range: 63-85 years). The Odor Stick Identification Test for Japanese, consisting of 12 odors, was used to examine olfaction. Subjects also completed physical performance (lower limb function, balance, and gait speed) and cognitive function (global cognition, logical memory, and the Trail Making Tests). Additionally, magnetic resonance imaging was used to investigate brain atrophy in the bilateral medial temporal area (MTA) and whole gray matter using the voxel-based specific regional analysis system for Alzheimer's disease.

Results: Total olfaction was not significantly associated with physical performance, cognitive function, or brain atrophy. However, MTA atrophy was associated with an inability to identify Japanese orange (B: $-0.293 ; \beta:-0.347$; $p<.05)$ after adjusting for age and sex $\left(R^{2}: 0.328\right.$; adjusted $\left.R^{2}: 0.277\right)$. Subjects who were unable to identify Japanese orange $(n=30)$ had worse MTA atrophy than those who were able to identify Japanese orange $(n=14)$, even after adjusting for covariates $(p<.05)$.
\end{abstract}

Conclusions: Total olfaction was not associated with physical performance, cognitive function, or brain atrophy. However, an inability to identify Japanese orange odor was independently associated with mild MTA atrophy among community-dwelling older adults.

Keywords: Olfactory dysfunction, Orange, Hippocampus, Entorhinal cortex, Amygdala

\footnotetext{
*Correspondence: yujiros.day.717@gmail.com; higaki@fukuoka-u.ac.jp

'Faculty of Sports and Health Science, Fukuoka University, 8-19-1 Nanakuma, Jonan-ku, Fukuoka 814-0180, Japan

Full list of author information is available at the end of the article
}

C C The Author(s). 2021 Open Access This article is licensed under a Creative Commons Attribution 4.0 International License, which permits use, sharing, adaptation, distribution and reproduction in any medium or format, as long as you give appropriate credit to the original author(s) and the source, provide a link to the Creative Commons licence, and indicate if changes were made. The images or other third party material in this article are included in the article's Creative Commons licence, unless indicated otherwise in a credit line to the material. If material is not included in the article's Creative Commons licence and your intended use is not permitted by statutory regulation or exceeds the permitted use, you will need to obtain permission directly from the copyright holder. To view a copy of this licence, visit http://creativecommons.org/licenses/by/4.0/ The Creative Commons Public Domain Dedication waiver (http://creativecommons.org/publicdomain/zero/1.0/) applies to the data made available in this article, unless otherwise stated in a credit line to the data. 


\section{Introduction}

Parkinson's disease (PD) and [1] Alzheimer's disease (AD) are well known neurodegenerative diseases. Olfactory dysfunction is a common non-motor symptom in PD. [2] It is also a predictive marker of dementia in PD patients [3], the development of $\mathrm{AD}$ [4], and progression from mild cognitive impairment (MCI) and amnestic $\mathrm{MCI}$ to dementia and AD dementia, respectively [5]. Olfactory dysfunction is also associated with memory loss in Japanese individuals with MCI [6].

Recently, it has been reported that cholinergic dysfunction is associated with poor gait performance in PD patients $[7,8]$, as well as with poor physical performance (mobility, balance, fine motor function, and manual dexterity) in community-dwelling older adults, independently of cognitive function [9]. Furthermore, olfactory function can reportedly be used to predict mortality [10].

However, hyposmia is often silent, even when it is severe/advanced. Takeda et al. suggested that PD patients are often not aware of their own hyposmia, and that hyposmia is often overlooked in the clinic unless olfactory tests are performed [11]. Unfortunately, olfactory examinations are not usually included in common medical checkup packages, and are thus not well known in the general population. However, if an inability to identify any common, familiar odor(s) is associated with impaired physical performance, cognitive dysfunction, and/ or brain atrophy, this may help older adults to become aware of physical and/or brain dysfunction at an earlier stage. Previous reports of the association between olfaction and physical and cognitive performance in community-dwelling older adults are scarce. Moreover, to our knowledge, it remains unknown whether an inability to identify any particular odor(s) is associated with cognitive impairment, physical dysfunction, or brain atrophy in such adults.

We thus aimed to conduct a cross-sectional study to investigate whether the ability to identify particular odors is associated with physical performance, cognitive function, and/or brain atrophy in community-dwelling older adults.

\section{Methods}

\section{Study population}

The geographic area of this cross-sectional study was "Island City" (Higashi-ku, Fukuoka, Japan; known as the Fukuoka Island City Study) [12, 13]. We included 44 physically independent subjects (14 males, 30 females; mean age: $72.4 \pm 5.7$ years, range: $63-85$ years). The measurement period was from July 2015 to August 2015. The study protocol has been previously described by Takae et al. [12, 13]. The study was conducted according to the guidelines of the Declaration of Helsinki, and all procedures involving human participants were approved by the Ethics Committee of Fukuoka University, Japan (approval no. 15-04-02). The purpose, procedures, and risks of the study were explained to each subject. All subjects provided written informed consent before entering into the study.

\section{Olfaction}

We examined smell identification function using the Odor Stick Identification Test for Japanese (OSIT-J; Daiichi Yakuhin Sangyo Co., Ltd., Tokyo, Japan) [14, 15]. The tests included five clusters and 12 odors. The clusters consisted of wood, grass, and herbs (Indian ink, wood, menthol, and Japanese cypress [hinoki]), sweet odors (perfume, rose, Japanese orange, and condensed milk), spices (roasted garlic and curry), gas (cooking gas), and excreta (fermented beans/sweaty socks). These odorants are everyday odors that are familiar to the Japanese population. Each odorant consisted of a solid cream enclosed in microcapsules, shaped like a lipstick.

For this test, each subject first received a piece of folded paraffin paper with one of the 12 odorants rubbed onto it. The subject then lifted the paper close to their nose, opened the paper, and sniffed the odorant. Next, the subject was asked to choose from six possible answers; either "unknown", "not detected", or one of four possible answers (consisting of the correct odorant and three other odorants). Each subject repeated these experimental procedures until all 12 odorant sticks had been examined. These methods followed those described by Iijima et al. [16].

We assessed olfaction in three ways: 1) total olfaction, which consisted of the number of correct answers (a score of $0-12)$; 2) tertiles of total olfaction, in which subjects were divided into tertiles by sex (male: T1-T3, female: T1-T3), and then males and females were combined by tertile group; and 3) the ability to identify particular odors. We scored each odor as 0 (incorrect answer) or 1 (correct answer), and a higher score indicated better olfaction.

\section{Brain atrophy}

Magnetic resonance imaging (MRI) was performed using a $3 \mathrm{~T}$ system (Magnetom Skyra; Simens, Munich, Germany). Three-dimensional volumetric acquisition of T1-weighted gradient-echo sequences produced a gapless series of thin sagittal sections, using a magnetization preparation with rapid acquisition (inversion time, 800 $\mathrm{ms}$; echo time, $2.92 \mathrm{~ms}$; repetition time, $1800 \mathrm{~ms}$; slice thickness, $1 \mathrm{~mm}$ ).

We investigated the degree of brain atrophy using voxel-based specific region analysis for AD (VSRAD) Advance 2 software (Eisai, Tokyo, Japan). VSRAD is a voxel-based MRI analysis software system based on 
SPM8 plus diffeomorphic anatomical registration through exponentiated Lie algebra [17, 18]. VSRAD Advance 2 automatically calculates z-scores for brain atrophy, which reflect the severity of gray matter atrophy in the whole brain compared with an original database consisting of date from 80 healthy volunteers with no memory impairments or cognitive disorders (37 males, 43 females; mean age: $70.4 \pm 7.8$ years, range: $54-86$ years) [18]. The z-score was defined as (control mean individual value) / (control standard deviation [SD]). We used four VSRAD Advance indicators: (i) severity of average atrophy in the bilateral medial temporal area, including the hippocampus, part of the amygdala, and the entorhinal cortex; and (ii) significant atrophy of gray matter in the whole brain (\%). Atrophy of the medial temporal area was judged based on z-scores: 0-1 (low atrophy), 1-2 (mild atrophy), 2-3 (moderate atrophy), and $>3$ (severe atrophy). Lower $\mathrm{z}$-scores indicated less atrophy.

\section{Cognitive function tests}

We used four index cognitive function tests to measure global cognitive function, logical memory, and executive function. All tests were performed by a trained staff member with one-to-one interaction.

Global cognition was tested using a simple test battery for AD screening in community-based settings [19]. This test consisted of 15 points in total, and was made up of four category tasks: an immediate memory test, temporal orientation test, three-dimensional visuospatial perception test, and delayed recall test.

Logical memory was assessed using the Wechsler Memory Scale-Revised (WMS-R) Logical Memory Immediate (LM-I) subtest, which has a maximum possible score of 25 . For this test, a short story was read aloud to the subject, who was then immediately asked to recall details of the story.

The Trail Making Tests A and B (TMT-A and TMTB) [20] were used to assess executive function, and particularly processing speed. For these tests, the complete time taken (in seconds) to complete each task was documented. A lower score in these tests indicated a better performance. In the TMT-A, subjects were asked to draw a line between encircled numbers $(1,2,3,4 \ldots)$, whereas in the TMT-B, they alternated between encircled numbers and Japanese letters $\left(1-\frac{\hbar}{-}, 2-\downarrow \ldots\right)$ to assess set-shifting. Faster TMT scores indicated a better performance.

\section{Physical performance}

We performed four index physical performance tests to measure lower limb muscle power, balance, and gait performance. The protocols that were used followed those described by Kimura et al. [21] and Takae et al. [13].
For the chair stand test, subjects sat on a chair $(0.43 \mathrm{~m}$ high) without armrests. They sat barefoot and with their arms folded. The subjects then performed a sit-to-stand movement five times as fast as possible, and the time from the initial seated position to the final seated position (after completing five standing movements) was measured. A shorter time indicated a better performance.

For the one leg standing (with open eyes) test, the amount of time that the subject was able to balance on one foot with their eyes open was measured using a stopwatch. For this test, subjects were barefoot and placed their hands on their hips. They were instructed not to let their legs touch each other, and were not allowed to move the foot that was standing on the floor.

Preferred and maximal gait speed: subjects walked 10 $\mathrm{m}$ (the first $2 \mathrm{~m}$ was included as acceleration and the last $2 \mathrm{~m}$ as deceleration) at a comfortable pace, and then at their fastest pace. The 6-m walking time was measured using a phototube. The walking time was measured twice for each test and the average was used. We then calculated the walking speed $(\mathrm{m} / \mathrm{s})$ from the $6-\mathrm{m}$ times.

\section{Physical parameters and comorbidities}

The height and weight of each subject were measured using a standard stadiometer and scales, respectively. The body mass index (BMI) was calculated as weight $(\mathrm{kg}) /$ height $(\mathrm{cm})^{2}$. Symptoms of depression were tested using the Geriatric Depression Scale (GDS) [22]. Data regarding comorbidities (diabetes mellitus, hypertension, and hyperlipidemia) were self-reported. Diabetes mellitus was determined by a self-report of diabetes mellitus, based on the self-report of a doctor's diagnosis and/or $\mathrm{HbA1c}$ level, obtained by finger-stick testing with commercial kits (Mitsubishi Chemical Medience, Tokyo, Japan).

\section{Statistical analysis}

The unpaired $t$-test was used to compare physical parameters, gait speed, cognitive function, brain atrophy, and olfaction, divided by sex and Japanese orange groups.

The chi-squared test was used to compare comorbidities and the accuracy rates of types of odors divided by sex. It was also used to compare comorbidities among the total olfaction tertile groups and Japanese orange groups.

Analysis of variance (ANOVA) was performed to compare olfaction, physical parameters, gait speed, cognitive function, and brain atrophy among the total olfaction tertile groups.

Analysis of covariance (ANCOVA) was performed to compare olfaction, physical parameters, gait speed, cognitive function, and brain atrophy among the total 
olfaction tertile groups adjusted for age and sex. It was also used to compare physical parameters, physical performance, cognitive function, and brain atrophy among the Japanese orange groups adjusted for age and sex. In addition, ANCOVA was used to examine the effects of independent covariates on atrophy of the medial temporal area among groups in adjusted models (model A: adjusted for age, sex, body mass index, GDS, diabetes mellitus, hyperlipemia, and hypertension; model B: adjusted for model A, global cognition, WMS-R LM-I, TMT-A, and TMT-B; model C: adjusted for model B, chair stand, one leg standing (with open eyes) test, preferred gait speed, and maximal gait speed; model D: adjusted for model $\mathrm{C}$ and whole gray matter atrophy).

Multiple regression (stepwise) analysis was performed to analyze whether physical performance, cognitive function, and brain atrophy were associated with the ability to identify particular odors, as independent covariates. This analysis consisted of three steps: step A: forced entry of covariates (age and sex); step B: stepwise entry of covariates (height, weight, body mass index, GDS, diabetes mellitus, hyperlipemia, and hypertension); and step C: stepwise entry of predictor variables (Indian ink, wood, menthol, Japanese cypress, perfume, rose, Japanese orange, condensed milk, roasted garlic, curry, cooking gas, and fermented beans/sweaty socks).

$p<.05$ was considered to represent statistical significance. Analyses were performed using SPSS v26 for Windows (IBM Corp., Armonk, NY).

\section{Results}

\section{Subject parameters based on sex}

The subjects' physical parameters, comorbidities, physical performance, cognitive function, and brain atrophy divided by sex are shown in Table 1 . Height and weight were significantly higher in males than in females

Table 1 Subject parameters divided by sex

\begin{tabular}{|c|c|c|c|c|}
\hline Variables & $\begin{array}{l}\text { All } \\
n=44\end{array}$ & $\begin{array}{l}\text { Male } \\
n=14\end{array}$ & $\begin{array}{l}\text { Female } \\
n=30\end{array}$ & $p$ \\
\hline \multicolumn{5}{|c|}{ Physical parameters, mean $\pm S D$} \\
\hline Age, years & $72.4 \pm 5.7$ & $71.2 \pm 5.8$ & $72.9 \pm 5.6$ & .366 \\
\hline Height, cm & $153.2 \pm 8.3$ & $162.2 \pm 5.7$ & $149.0 \pm 5.4$ & .000 \\
\hline Weight, kg & $53.7 \pm 11.1$ & $61.8 \pm 11.2$ & $50.0 \pm 8.9$ & .000 \\
\hline $\mathrm{BMI}, \mathrm{kg} / \mathrm{m}^{2}$ & $22.8 \pm 3.6$ & $23.4 \pm 3.3$ & $22.5 \pm 3.8$ & .445 \\
\hline GDS, score ${ }^{a}$ & $2.7 \pm 2.5$ & $1.8 \pm 1.5$ & $3.1 \pm 2.7$ & .040 \\
\hline \multicolumn{5}{|l|}{ Comorbidities, n (\%) } \\
\hline Diabetes mellitus & $17(39)$ & $7(50)$ & $10(33)$ & .290 \\
\hline Hyperlipemia & $12(27)$ & $2(14)$ & $10(33)$ & .186 \\
\hline Hypertension & $10(23)$ & $0(0)$ & $10(33)$ & .014 \\
\hline \multicolumn{5}{|c|}{ Physical performance, mean $\pm S D$} \\
\hline Five times $C S, s^{a}$ & $7.2 \pm 1.8$ & $7.0 \pm 1.5$ & $7.3 \pm 1.9$ & .641 \\
\hline OLS, s & $49.0 \pm 39.9$ & $56.2 \pm 49.6$ & $45.7 \pm 34.9$ & .481 \\
\hline Preferred GS, m/s & $1.28 \pm 0.20$ & $1.26 \pm 0.20$ & $1.29 \pm 0.21$ & .633 \\
\hline Maximal GS, m/s & $1.77 \pm 0.25$ & $1.86 \pm 0.22$ & $1.72 \pm 0.25$ & .081 \\
\hline \multicolumn{5}{|c|}{ Cognitive function, mean $\pm S D$} \\
\hline Global cognition, score & $14.0 \pm 1.5$ & $14.1 \pm 1.8$ & $13.9 \pm 1.3$ & .773 \\
\hline WMS-R LM-I, score & $8.7 \pm 4.1$ & $8.0 \pm 4.7$ & $9.1 \pm 3.9$ & .431 \\
\hline TMT-A, $s^{a}$ & $96.8 \pm 35.9$ & $97.4 \pm 39.4$ & $96.5 \pm 34.8$ & .940 \\
\hline TMT-B, sa & $133.6 \pm 69.6$ & $134.1 \pm 87.2$ & $133.4 \pm 61.4$ & .974 \\
\hline \multicolumn{5}{|c|}{ Brain atrophy, z-score, mean $\pm S D$} \\
\hline Medial temporal area $^{\mathrm{a}}$ & $0.77 \pm 0.40$ & $0.89 \pm 0.47$ & $0.71 \pm 0.35$ & .161 \\
\hline GM in the whole brain ${ }^{a}$ & $3.66 \pm 1.50$ & $4.07 \pm 1.95$ & $3.46 \pm 1.23$ & .297 \\
\hline
\end{tabular}

For the physical parameters, physical performance, cognitive function, and brain atrophy, the $p$-value for male vs. female was calculated using an unpaired t-test For the comorbidities, the $p$-value for male vs. female was calculated using a chi-squared test

BMI body mass index, GDS Geriatric Depression Scale, SD standard deviation, CS chair stand, OLS one leg standing with open eyes, GS gait speed, TMT Trail Making Test, WMS-R LM Wechsler Memory Scale-Revised Logical Memory Immediate, GM gray matter

a Lower scores indicate better performance 
$(p<.05$ for both). GDS and hypertension were significantly higher in females than in males ( $p<.05$ for both).

\section{Olfaction parameters based on sex}

The total olfaction score was not significantly different between males and females $(p=.178)$ (Table 2). For the accuracy rate of each odor, the accuracy rates for wood and condensed milk were significantly higher in females than in males $(p<.05$ for both).

\section{Parameters and performance in the total olfaction tertiles}

Sex, comorbidities, physical parameters, physical performance, cognitive function, and brain atrophy were not significantly different between the olfaction tertile groups using ANOVA (Table 3). Worse TMT-A and TMT-B scores were associated with worse total olfaction scores $(p<.05$ for the trend score). However, after adjusting for age and sex, there were no significant associations between any variables and the olfaction tertile groups, and no significant trend scores.

\section{Multiple regression (stepwise) analysis for predicting physical performance, cognitive function, and brain atrophy from the identification of different odors} Greater atrophy of the medial temporal area was significantly associated with an inability to identify Japanese orange, even after adjusting for age and sex $\left(R^{2}: 0.328\right.$; adjusted $R^{2}$ : 0.277; B: $-0.293 ; \beta:-0.347 ; 95 \%$ confidence interval: $-0.515,-0.071 ; p<.05$ ) (Table 4). However, worse performances in the chair stand, one leg standing (with open eyes) test, preferred or maximal gait speed, global cognition, WMS-R LM-I, TMT-A, TMT-B, and whole gray matter atrophy were not significantly associated with an inability to identify any particular odor after adjusting for age and sex.

\section{Parameters and performance divided by the ability to identify Japanese orange}

An inability to identify Japanese orange $(n=30)$ was associated with greater atrophy of the medial temporal area compared with the ability to identify Japanese orange $(n=14)$, but was not significantly associated with any other variables (Table 5). This association was significant even after adjusting for age, sex, GDS, comorbidities, cognition, physical performance, and whole gray matter atrophy $(p<.05)$.

\section{Discussion}

Total olfaction scores were not significantly associated with physical performance, cognitive function, or brain atrophy in the present study. Only the inability to identify Japanese orange was significantly associated with mild atrophy of the medial temporal area among Japanese community-dwelling older adults, independent of

Table 2 Olfaction parameters divided by sex

\begin{tabular}{|c|c|c|c|c|}
\hline Variables & $\begin{array}{l}\text { All } \\
n=44\end{array}$ & $\begin{array}{l}\text { Male } \\
n=14\end{array}$ & $\begin{array}{l}\text { Female } \\
n=30\end{array}$ & $p$ \\
\hline Total score, mean $\pm S D$ & $6.8 \pm 3.3$ & $5.9 \pm 3.5$ & $7.3 \pm 3.1$ & .178 \\
\hline \multicolumn{5}{|l|}{ Wood, grass, and herb } \\
\hline Indian ink & $23(52)$ & $6(43)$ & $17(57)$ & .393 \\
\hline Wood & $27(61)$ & $5(36)$ & $22(73)$ & .017 \\
\hline Menthol & $23(52)$ & $7(50)$ & $16(53)$ & .837 \\
\hline Japanese cypress (hinoki) & $21(48)$ & $8(57)$ & $13(43)$ & .393 \\
\hline \multicolumn{5}{|l|}{ Sweet } \\
\hline Perfume & $27(61)$ & $6(43)$ & $21(70)$ & .085 \\
\hline Rose & $26(59)$ & $7(50)$ & $19(63)$ & .402 \\
\hline Japanese orange & $14(32)$ & $5(36)$ & $9(30)$ & .705 \\
\hline Condensed milk & $26(59)$ & $5(36)$ & $21(70)$ & .031 \\
\hline \multicolumn{5}{|l|}{ Spices } \\
\hline Roasted garlic & $27(61)$ & $8(57)$ & $19(63)$ & .694 \\
\hline Curry & $34(77)$ & $10(71)$ & $24(80)$ & .527 \\
\hline \multicolumn{5}{|l|}{ Gas } \\
\hline Cooking gas & $26(59)$ & $7(50)$ & $19(63)$ & .402 \\
\hline \multicolumn{5}{|l|}{ Excreta } \\
\hline Fermented beans/sweaty socks & $27(61)$ & $8(57)$ & $19(63)$ & .694 \\
\hline
\end{tabular}

For the total score, the $\mathrm{p}$-value for male vs. female was calculated using an un-paired t-test For each of the 12 odors, the p-value for male vs. female was calculated using a chi-squared test $S D$ standard deviation. The total score consists of the number of correct answers for the 12 odors 
Table 3 Subject parameters and performance in each total olfaction tertile

\begin{tabular}{|c|c|c|c|c|c|c|c|}
\hline \multirow[b]{2}{*}{ Variables } & \multicolumn{3}{|c|}{ Tertile of total olfaction } & \multicolumn{2}{|c|}{ Crude } & \multicolumn{2}{|c|}{ Adjusted for age and sex } \\
\hline & $\mathrm{T} 1, n=18$ & $T 2, n=13$ & $\mathrm{~T} 3, n=13$ & $\bar{p}$ & $\overline{\text { Trend }}$ & $p$ & Trend \\
\hline Total olfaction score, mean \pm SD & $3.9 \pm 2.7$ & $7.6 \pm 1.6$ & $10.2 \pm 0.8$ & .000 & .000 & & \\
\hline Sex, female (\%) & $13(72)$ & $8(62)$ & $9(69)$ & .816 & .820 & - & - \\
\hline \multicolumn{8}{|l|}{ Comorbidities, n (\%) } \\
\hline Diabetes mellitus & $5(28)$ & $6(46)$ & $6(46)$ & .469 & .281 & - & - \\
\hline Hyperlipemia & $6(33)$ & $2(15)$ & $4(31)$ & .512 & .798 & - & - \\
\hline Hypertension & $4(22)$ & $4(31)$ & $2(15)$ & .644 & .712 & - & - \\
\hline \multicolumn{8}{|l|}{ Physical parameters, mean $\pm S D$} \\
\hline Age, years & $73.0 \pm 6.2$ & $74.4 \pm 5.5$ & $69.5 \pm 4.0$ & .069 & .082 & - & - \\
\hline Height, cm & $153.8 \pm 8.9$ & $151.5 \pm 9.7$ & $154.2 \pm 5.9$ & .678 & .889 & .222 & .787 \\
\hline Weight, kg & $54.1 \pm 12.6$ & $52.9 \pm 10.5$ & $54.0 \pm 10.3$ & .951 & .981 & .831 & .650 \\
\hline $\mathrm{BMI}, \mathrm{kg} / \mathrm{m}^{2}$ & $22.8 \pm 4.3$ & $22.9 \pm 2.8$ & $22.7 \pm 3.7$ & .988 & .907 & .929 & .744 \\
\hline GDS, score ${ }^{a}$ & $3.1 \pm 2.7$ & $3.1 \pm 2.8$ & $1.8 \pm 1.6$ & .270 & .139 & .421 & .228 \\
\hline \multicolumn{8}{|l|}{ Physical performance, mean $\pm S D$} \\
\hline Five times $C S, s^{a}$ & $7.8 \pm 2.0$ & $6.9 \pm 1.5$ & $6.8 \pm 1.6$ & .262 & .163 & .241 & .450 \\
\hline OLS, s & $43.9 \pm 34.8$ & $41.3 \pm 42.2$ & $63.9 \pm 43.1$ & .281 & .173 & .682 & .421 \\
\hline Preferred GS, m/s & $1.26 \pm 0.22$ & $1.24 \pm 0.18$ & $1.36 \pm 0.19$ & .260 & .187 & .404 & .252 \\
\hline Maximal GS, m/s & $1.71 \pm 0.25$ & $1.76 \pm 0.28$ & $1.86 \pm 0.19$ & .222 & .086 & .457 & .220 \\
\hline \multicolumn{8}{|l|}{ Cognitive function, mean $\pm S D$} \\
\hline Global cognition, score & $13.8 \pm 1.7$ & $13.7 \pm 1.5$ & $14.5 \pm 0.8$ & .255 & .155 & .682 & .404 \\
\hline WMS-R LM-I, score & $7.4 \pm 3.9$ & $9.2 \pm 4.3$ & $10.1 \pm 3.9$ & .178 & .076 & .220 & .154 \\
\hline TMT-A, $s^{a}$ & $106.3 \pm 41.7$ & $103.5 \pm 36.4$ & $76.9 \pm 14.5$ & .054 & .023 & .250 & .098 \\
\hline TMT-B, $s^{a}$ & $160.1 \pm 95.6$ & $124.3 \pm 39.6$ & $106.1 \pm 29.5$ & .085 & .033 & .112 & .145 \\
\hline \multicolumn{8}{|l|}{ Brain atrophy, z-score, mean $\pm S D$} \\
\hline Medial temporal area ${ }^{a}$ & $0.84 \pm 0.35$ & $0.79 \pm 0.46$ & $0.66 \pm 0.40$ & .459 & .223 & .682 & .533 \\
\hline GM in the whole brain ${ }^{a}$ & $3.71 \pm 1.65$ & $3.78 \pm 1.67$ & $3.46 \pm 1.17$ & .850 & .653 & .984 & .873 \\
\hline
\end{tabular}

Crude: analysis of variance (ANOVA). Adjusted age and gender: analysis of covariance (ANCOVA)

$B M I$ body mass index, GDS Geriatric Depression Scale, SD standard deviation, CS chair stand, OLS one leg standing with open eyes, GS gait speed, TMT Trail Making Test, WMS-R LM Wechsler Memory Scale-Revised Logical Memory Immediate, GM gray matter

a Lower scores indicate better performance

physical parameters, physical performance, cognitive function, and atrophy of the whole gray matter.

Several previous studies have suggested that cholinergic dysfunction is associated with poor gait performance in PD patients $[7,8]$. However, there have been few previous studies investigating normally aging older adults. Tian et al. used challenging upper and lower extremity motor function tasks to demonstrate that olfactory function is associated with mobility, balance, fine motor function, and manual dexterity, but is independent of cognitive function. In addition, changes in olfactory function may provide insights into the earliest agerelated changes in the brain, which may relate to the neural aspects of age-related movement decline [9].

One of our hypotheses was that worse total olfaction would be associated with worse physical performance, cognitive function, and brain atrophy. Surprisingly, however, the present study revealed that the total olfaction score was not associated with physical performance, cognitive function, or brain atrophy. The reasons for the differences between our results and those of Tian et al. [9] are unclear. One possible reason may be because our study subjects (aged 72.4 \pm 5.7 years) were younger than those in the study by Tian et al. (aged $77.4 \pm 8.5$ years); aging is known to be a strong risk factor for olfactory dysfunction [23]. In addition, several previous longitudinal studies have suggested that olfactory function is a predictor of mortality [10], verbal memory [24], perceptual speed, and episodic memory [25] in subjects without dementia. It is therefore reasonable that our study revealed no association between olfaction and physical performance, cognitive function, or brain atrophy in a cross-sectional study among community-dwelling older adults. Additional studies are needed to investigate 
Table 4 Multiple regression (stepwise) analysis for predicting physical performance, cognitive function, and brain atrophy from the identification of different odors

\begin{tabular}{|c|c|c|c|c|c|c|c|c|c|}
\hline \multirow[b]{2}{*}{ Predicted variables } & \multirow{2}{*}{$\begin{array}{l}\text { [Step A] } \\
\text { Forced entry }\end{array}$} & \multirow{2}{*}{$\begin{array}{l}\text { [Step B] } \\
\text { Stepwise }\end{array}$} & \multirow{2}{*}{$\begin{array}{l}\text { [Step C] } \\
\text { Stepwise }\end{array}$} & \multicolumn{6}{|c|}{ Final model status } \\
\hline & & & & Variables & B & $\beta$ & $95 \% \mathrm{Cl}$ for $\mathrm{B}$ & $R^{2}$ & $\operatorname{adj}-R^{2}$ \\
\hline \multicolumn{10}{|l|}{ Physical performance } \\
\hline \multirow[t]{4}{*}{ Five times chair stand } & Age & & & Age & 0.141 & 0.449 & $0.055,0.228^{*}$ & .304 & .252 \\
\hline & Sex & & & Sex & 0.973 & 0.256 & $-0.201,2.15$ & & \\
\hline & & Weight & & Weight & 0.079 & 0.488 & $0.028,0.130^{*}$ & & \\
\hline & & & - & Constant & -8.88 & & $-16.8,-0.97^{*}$ & & \\
\hline \multirow[t]{4}{*}{ One leg standing with open eyes } & Age & & & Age & -2.90 & -0.414 & $-4.77,-1.03^{*}$ & .324 & .273 \\
\hline & Sex & & & Sex & -9.90 & -0.117 & $-32.5,12.7$ & & \\
\hline & & BMI & & BMl & -4.64 & -0.422 & $-7.56,-1.71^{*}$ & & \\
\hline & & & - & Constant & 381.4 & & $222.1,540.8^{*}$ & & \\
\hline \multirow[t]{3}{*}{ Preferred gait speed } & Age & & & Age & -0.005 & -0.152 & $-0.016,0.006$ & .028 & -.019 \\
\hline & Sex & & & Sex & 0.041 & 0.095 & $-0.093,0.175$ & & \\
\hline & & - & - & Constant & 1.60 & & $0.796,2.41^{*}$ & & \\
\hline \multirow[t]{3}{*}{ Maximal gait speed } & Age & & & Age & -0.014 & -0.330 & $-0.027,-0.002^{*}$ & .178 & .138 \\
\hline & Sex & & & Sex & -0.115 & -0.220 & $-0.266,0.036$ & & \\
\hline & & - & - & Constant & 2.99 & & $2.09,3.90^{*}$ & & \\
\hline \multicolumn{10}{|l|}{ Cognitive function } \\
\hline \multirow[t]{3}{*}{ Global cognition } & Age & & & Age & -0.101 & -0.397 & $-0.176,-0.027^{*}$ & .156 & .115 \\
\hline & Sex & & & Sex & 0.033 & 0.011 & $-0.870,0.936$ & & \\
\hline & & - & - & Constant & 21.3 & & $15.8,26.7^{*}$ & & \\
\hline \multirow[t]{3}{*}{ WMS-R LM-I } & Age & & & Age & -0.163 & -0.225 & $-0.387,0.060$ & .064 & .019 \\
\hline & Sex & & & Sex & 1.34 & 0.153 & $-1.36,4.04$ & & \\
\hline & & - & - & Constant & 18.3 & & $2.06,34.5^{*}$ & & \\
\hline \multirow[t]{4}{*}{ TMT-A } & Age & & & Age & 2.74 & 0.434 & $1.03,4.45^{*}$ & .300 & .247 \\
\hline & Sex & & & Sex & -8.19 & -0.108 & $-28.9,12.5$ & & \\
\hline & & BMI & & BMl & -2.95 & -0.299 & $-5.6,-0.30^{*}$ & & \\
\hline & & & - & Constant & -105.8 & & $-235.2,23.6$ & & \\
\hline \multirow[t]{3}{*}{ TMT-B } & Age & & & Age & 5.69 & 0.465 & $2.24,9.15^{*}$ & .212 & .174 \\
\hline & Sex & & & Sex & -10.3 & -0.070 & $-52.1,31.4$ & & \\
\hline & & - & - & Constant & -261.1 & & $-512.1,-10.0^{*}$ & & \\
\hline \multicolumn{10}{|l|}{ Brain atrophy } \\
\hline \multirow[t]{4}{*}{ Medial temporal area } & Age & & & Age & 0.030 & 0.424 & $0.011,0.048^{*}$ & .328 & .277 \\
\hline & Sex & & & Sex & -0.248 & -0.294 & $-0.472,-0.024^{*}$ & & \\
\hline & & - & J orange & J orange & -0.293 & -0.347 & $-0.515,-0.071^{*}$ & & \\
\hline & & & & Constant & -0.863 & & $-2.21,0.480$ & & \\
\hline \multirow[t]{3}{*}{ Gray matter in the whole brain } & Age & & & Age & 0.052 & 0.198 & $-0.029,0.133$ & .075 & .030 \\
\hline & Sex & & & Sex & -0.697 & -0.219 & $-1.67,0.279$ & & \\
\hline & & - & - & Constant & 1.05 & & $-4.82,6.91$ & & \\
\hline
\end{tabular}

Type of odors inversed 1 (correct answer) or 0 (un-correct answer)

B: unstandardized regression coefficient, $\beta$ : standardized regression coefficient, Cl: confidence interval, adj-R2: adjusted-R2

Step A covariates consisted of age and gender in a forced entry analysis

Step B covariates consisted of height, weight, BMI, Geriatric Depression Scale, diabetes mellitus, hyperlipemia, and hypertension in a stepwise analysis

Step C predictors consisted of types of odors: Indian ink, wood, menthol, Japanese cypress (hinoki), perfume, rose, Japanese orange, roast garlic, curry, cooking

gas, fermented beans/sweaty socks, and condensed milk in a stepwise analysis

BMI body mass index, OLS one leg standing with open eyes, J orange Japanese orange, TMT Trail Making Test, WMS-R LM-I Wechsler Memory Scale-Revised Logical

Memory Immediate

${ }^{*} P<0.05$ as a predictor in final models 
Table 5 Subject parameters divided by the ability to identify Japanese orange odor (correct/incorrect)

\begin{tabular}{|c|c|c|c|c|c|c|c|c|}
\hline \multirow[t]{3}{*}{ Variables } & \multirow{3}{*}{$\begin{array}{l}\text { Correct } \\
n=14\end{array}$} & \multirow{3}{*}{$\begin{array}{l}\text { Incorrect } \\
n=30\end{array}$} & \multicolumn{6}{|l|}{$p$-value } \\
\hline & & & \multirow[t]{2}{*}{ Crude } & \multirow{2}{*}{$\begin{array}{l}\text { Adjusted } \\
\text { for age } \\
\text { and sex }\end{array}$} & \multicolumn{4}{|c|}{ Adjusted models for medial temporal area atrophy } \\
\hline & & & & & $\begin{array}{l}\text { Model } \\
\text { A }\end{array}$ & $\begin{array}{l}\text { Model } \\
\text { B }\end{array}$ & $\begin{array}{l}\text { Model } \\
\text { C }\end{array}$ & $\begin{array}{l}\text { Model } \\
\text { D }\end{array}$ \\
\hline Sex, female (\%) & $9(64)$ & $21(70)$ & .705 & - & & & & \\
\hline \multicolumn{9}{|l|}{ Comorbidities, $n$ (\%) } \\
\hline Diabetes mellitus & $6(43)$ & $11(37)$ & 694 & - & & & & \\
\hline Hyperlipemia & $4(29)$ & $8(27)$ & .895 & - & & & & \\
\hline Hypertension & $3(21)$ & $7(23)$ & .888 & - & & & & \\
\hline \multicolumn{9}{|l|}{ Physical parameters, mean $\pm S D$} \\
\hline Age, years & $72.7 \pm 5.7$ & $72.2 \pm 5.8$ & .784 & - & & & & \\
\hline Height, cm & $152.3 \pm 9.3$ & $153.7 \pm 7.9$ & .605 & .255 & & & & \\
\hline Weight, kg & $56.2 \pm 12.3$ & $52.6 \pm 10.5$ & .319 & .315 & & & & \\
\hline $\mathrm{BMI}, \mathrm{kg} / \mathrm{m}^{2}$ & $24.1 \pm 3.9$ & $22.2 \pm 3.4$ & .112 & .118 & & & & \\
\hline GDS, score ${ }^{a}$ & $2.3 \pm 2.1$ & $2.9 \pm 2.6$ & .448 & .450 & & & & \\
\hline \multicolumn{9}{|l|}{ Physical performance, mean $\pm S D$} \\
\hline Five times $C S, s^{a}$ & $6.9 \pm 1.7$ & $7.4 \pm 1.9$ & .456 & .378 & & & & \\
\hline OLS, s & $50.2 \pm 38.2$ & $48.5 \pm 41.3$ & .899 & .830 & & & & \\
\hline Preferred GS, m/s & $1.21 \pm 0.05$ & $1.32 \pm 0.04$ & .103 & .124 & & & & \\
\hline Maximal GS, m/s & $1.76 \pm 0.07$ & $1.77 \pm 0.05$ & .896 & .896 & & & & \\
\hline \multicolumn{9}{|l|}{ Cognitive function, mean $\pm S D$} \\
\hline Global cognition, score & $14.1 \pm 1.4$ & $13.9 \pm 1.5$ & .773 & 669 & & & & \\
\hline WMS-R LM-I, score & $8.5 \pm 4.8$ & $8.8 \pm 3.9$ & .806 & .898 & & & & \\
\hline TMT-A, $s^{a}$ & $92.7 \pm 34.9$ & $98.7 \pm 36.7$ & .612 & .463 & & & & \\
\hline TMT-B, $s^{a}$ & $121.6 \pm 41.6$ & $139.2 \pm 79.4$ & .443 & .308 & & & & \\
\hline \multicolumn{9}{|l|}{ Brain atrophy, mean $\pm S D$} \\
\hline MTA, z-score ${ }^{a}$ & $0.59 \pm 0.40$ & $0.85 \pm 0.37$ & .039 & .011 & .007 & .009 & .022 & .0498 \\
\hline GM in the whole brain, $\%^{\mathrm{a}}$ & $3.17 \pm 1.37$ & $3.89 \pm 1.53$ & .140 & .099 & & & & \\
\hline
\end{tabular}

Crude: analysis of variance (ANOVA). Adjusted age and gender: analysis of covariance (ANCOVA)

Crude: un-paired t-test; adjusted models: analysis of covariance (ANCOVA)

Model A: ANCOVA adjusted for age, gender, body mass index, GDS, and comorbidities (diabetes mellitus, hyperlipemia, and hypertension)

Model B: ANCOVA adjusted for model A and cognitive function tests (global cognition, WMS-R LM-I, TMT-A, and TMT-B)

Model C: ANCOVA adjusted for model B and physical performance (five times chair stand, OLS, preferred gait speed, and maximal gait speed)

Model D: ANCOVA adjusted for model $C$ and gray matter atrophy in the whole brain

$B M I$ body mass index, GDS Geriatric Depression Scale, SD standard deviation, CS chair stand, OLS one leg standing with open eyes, GS gait speed, TMT Trail

Making Test, WMS-R LM Wechsler Memory Scale-Revised Logical Memory Immediate, MTA medial temporal area, GM gray matter

aLower scores indicate better performance

whether total olfaction scores are associated with physical performance, cognitive function, and/or brain atrophy in a larger number of community-dwelling older subjects, separated into the youngest older adults and the oldest older adults.

Previous studies into the association between olfaction and brain volume have reported a positive correlation between olfactory performance and gray matter volume in the right piriform cortex in early PD patients [26], and in the nucleus accumbens and left parahippocampal gyrus in very mild amnestic patients (aged 77.4 \pm 6.8 years) [27]. Furthermore, Bohnen et al. reported that olfactory dysfunction is positively correlated with acetylcholinesterase activity in the hippocampus, amygdala, and neocortex in PD patients [28]. However, although Hagemeier et al. reported that odor identification deficits are associated with lower volumes in the right hippocampus and left amygdala in amnestic MCI patients, and in the bilateral hippocampus and left amygdala in $\mathrm{AD}$, they found no/weak associations between odor identification and gray matter volume in cognitively normal subjects [29]. Hagemeier et al. suggested that the weak association between olfaction, global atrophy, and aging among cognitively normal subjects may indicate that such interactions are augmented by disease processes [29]. 
Shiga et al. reported that, in 243 Japanese adults (mean age 37.5 years, range 20-62 years), combinations of two odorants in the smell identification test can be used to screen olfactory impairment [30]. They concluded that the combination of Japanese cypress and Indian ink odorants may be useful for detecting individuals with olfactory impairment (total olfaction scores of $\leq 7$ ) among Japanese adults who are able to correctly identify the curry odorant. Moreover, Shiga et al. demonstrated that, for olfactory impairment screening with a single odorant, Japanese cypress had the highest positive likelihood ratio (5.2; sensitivity, 42.2\%; specificity, 91.9\%), while Japanese orange had the second-highest positive likelihood ratio (3.1; sensitivity, $11.1 \%$; specificity, $96.5 \%$ ) and the highest specificity of all odorants.

It is unclear why an inability to identify orange odor might be associated with atrophy in the medial temporal area. The prevalence of olfactory impairment increases with age [31, 32], and is higher in 80- to 97-year-old individuals $(62.5 \%)$ than in 70 - to 79 -year-old individuals (29.2\%) [32]. In subjects with similar ages (72.4 \pm 5.7 years) to those in the present study, Koskine and Tuorila reported that older subjects had a lower sensitivity to yogurt, but not to grape juice odors [33]. Interestingly, sensitivity to orange flavor (which is used commercially to flavor beverages) was reported to be 49 times lower in older subjects than in younger subjects [34]. These findings indicate that there is specificity of olfactory impairments, and suggest that recognizing orange in particular may be related to brain atrophy.

Japanese orange is an everyday, familiar food and odor to the Japanese population. Japanese oranges are smaller than the familiar oranges of most countries, but their flavors are similar. Thus, an inability to identify orange odor might be helpful for the early detection of silent, advanced hyposmia as well as atrophy of the medial temporal area, within both Japanese and non-Japanese populations. However, olfactory identification tests are not generally popular. This study may therefore help to increase the awareness of hyposmia among communitydwelling older adults in their everyday life.

One strength of our study was the novel finding of an association between an inability to identify Japanese orange and mild atrophy of the medial temporal area, including the hippocampus, part of the amygdala, and the entorhinal cortex. Notably, compared with subjects who were able to identify Japanese orange, subjects who were unable to identify Japanese orange had a similar age, sex ratio, comorbidities, physical performance, cognitive function, and atrophy of gray matter in the whole brain. These results suggest that an inability to identify orange odor is independently associated with silent, advanced atrophy of the medial temporal area. The individuals who were unable to identify Japanese orange would not be judged to have a high risk of dementia from the screening of physical performance and/or cognitive function. Therefore, an impairment in the identification of orange odor might be one of the earliest markers (before physical and cognitive dysfunction) of dementia and/or mortality among community-dwelling older adults. In the future, these findings need to be further defined by a longitudinal study, and the responsible pathways should also be explored.

The limitations of this study were as follows: (i) our cross-sectional study was unable to interpret cause and effect; (ii) it was unknown whether subjects had stroke or cardiovascular disease; (iii) it was unknown whether the characteristics of our study subjects reflected those of the general population; (iv) it was unclear whether our sample size was large enough in terms of statistical power; and (v) the association between olfaction and brain atrophy in non-Japanese subjects remains unclear.

\section{Conclusion}

An inability to identify specific odors (orange, in particular) was significantly associated with mild atrophy of the medial temporal area, including the hippocampus, part of the amygdala, and the entorhinal cortex, in community-dwelling older adults.

\section{Abbreviations \\ MTA: Medial temporal area; PD: Parkinson's disease; AD: Alzheimer's disease; MCl: Mild cognitive impairment; OSIT-J: The Odor Stick Identification Test for Japanese; MRI: Magnetic resonance imaging; VSRAD: Voxel-based specific region analysis for Alzheimer's disease; SD: Standard deviation; WMS-R: The Wechsler Memory Scale-Revised; LM-I: Logical Memory Immediate (LM-I); TMT: The Trail Making Test; BMI: Body mass index; GDS: The Geriatric Depression Scale; ANOVA: Analysis of variance; ANCOVA: Analysis of covariance}

\section{Acknowledgments}

We give our greatest thanks to Professor Hiroaki Tanaka (deceased), Emeritus Professor at Fukuoka University, Faculty of Sports and Health Science. He designed this study, made great efforts to promote the research, encouraged us, and passed away without seeing the completion of this manuscript. We include him in the acknowledgments because we are unable to include him as an author. We also thank the study participants, the mayor of Fukuoka city, the Port \& Airport Bureau staff, and the graduate students in our laboratory who assisted with data collection.

\section{Authors' contributions}

Y.K., Y.H., R.T. and Y.H. designed the study; Y.K., Y.H., R.T., Y.T., J.Y. and T.K. conducted the study; Y.K. analyzed the data; Y.K., Y.T. and Y. H interpreted the results; Y.K. and Y.T. wrote the manuscript; Y.K. and Y.H. were responsible for the design and final content of the article; and all authors read and approved the final manuscript.

\section{Funding}

This work was supported by Japan Society for the Promotion of Science KAKENHI (grant numbers 25242065, 19 K20132) from the Ministry of Education, Culture, Sports, Science, and Technology to the Fukuoka University Institute for Physical Activity.

\section{Availability of data and materials}

We used data collected by our research team (The Fukuoka University Institute for Physical Activity, Fukuoka University). The datasets obtained and/ or analysed during the current study are not publicly available and we are 
planning to publish more papers using the same dataset. The datasets are available from the corresponding author on reasonable request.

\section{Declarations}

\section{Ethics approval and consent to participate}

The study was conducted according to the guidelines of the Declaration of Helsinki, and all procedures involving human participants were approved by the Ethics Committee of Fukuoka University, Japan (approval no. 15-04-02). The purpose, procedures, and risks of the study were explained to each subject. All subjects provided written informed consent before entering into the study.

\section{Consent for publication}

Not applicable.

\section{Competing interests}

The authors declare no conflict of interest.

\section{Author details}

${ }^{1}$ Faculty of Sports and Health Science, Fukuoka University, 8-19-1 Nanakuma, Jonan-ku, Fukuoka 814-0180, Japan. ${ }^{2}$ The Fukuoka University Institute for Physical Activity, Fukuoka University, 8-19-1 Nanakuma, Jonan-ku, Fukuoka 814-0180, Japan. ${ }^{3}$ Department of Nutrition and Metabolism, National Institute of Health and Nutrition, National Institutes of Biomedical Innovation, Health, and Nutrition, 1-23-1 Toyama, Shinjuku-ku, Tokyo 162-8636, Japan. ${ }^{4}$ Faculty of Nursing and Nutrition, University of Nagasaki, Manabino 1-1-1, Nagayo-Cho, Nishisonogi-gun, Nagasaki 851-2195, Japan. ${ }^{5}$ Faculty of Human Sciences, University of East Asia, 2-1 Ichinomiyagakuen-cho, Yamaguchi 751-8503, Japan. ${ }^{6}$ Center for Education in Liberal Arts and Sciences, Osaka University, 1-17 Machikaneyamachou, Toyonaka, Osaka 560-0043, Japan.

Received: 5 March 2021 Accepted: 29 June 2021

Published online: 12 July 2021

\section{References}

1. Parkinson J. An essay on the shaking palsy. 1817. J Neuropsychiatry Clin Neurosci. 2002;14(2):223-36 discussion 222.

2. Ansari KA, Johnson A. Olfactory function in patients with Parkinson's disease. J Chronic Dis. 1975;28(9):493-7. https:/doi.org/10.1016/0021-9681(75)90058-2.

3. Baba T, Kikuchi A, Hirayama K, Nishio Y, Hosokai Y, Kanno S, et al. Severe olfactory dysfunction is a prodromal symptom of dementia associated with Parkinson's disease: a 3 year longitudinal study. Brain. 2012;135(Pt 1):161-9. https://doi.org/10.1093/brain/awr321.

4. Yaffe K, Freimer D, Chen H, Asao K, Rosso A, Rubin S, et al. Olfaction and risk of dementia in a biracial cohort of older adults. Neurology. 2017;88(5):45662. https://doi.org/10.1212/WNL.0000000000003558.

5. Roberts RO, Christianson TJ, Kremers WK, Mielke MM, Machulda MM, Vassilaki M, et al. Association between olfactory dysfunction and amnestic mild cognitive impairment and Alzheimer disease dementia. JAMA Neurol. 2016;73(1):93-101. https://doi.org/10.1001/jamaneurol.2015.2952.

6. Makizako M, Makizako H, Doi T, Uemura K, Tsutsumimoto K, Miyaguchi H, et al. Olfactory identification and cognitive performance in communitydwelling older adults with mild cognitive impairment. Chem Senses. 2014; 39(1):39-46. https://doi.org/10.1093/chemse/bjt052.

7. Bohnen NI, Frey KA, Studenski S, Kotagal V, Koeppe RA, Scott PJ, et al. Gait speed in Parkinson disease correlates with cholinergic degeneration. Neurology. 2013; 81(18):1611-6. https://doi.org/10.1212/WNL.0b013e3182a9f558.

8. Rochester L, Yarnall AJ, Baker MR, David RV, Lord S, Galna B, et al. Cholinergic dysfunction contributes to gait disturbance in early Parkinson's disease. Brain J Neurol. 2012;135(Pt 9):2779-88. https://doi.org/10.1093/brain/aws207.

9. Tian $Q$, Resnick SM, Studenski SA. Olfaction is related to motor function in older adults. J Gerontol A Biol Sci Med Sci. 2017;72(8):1067-71.

10. Pinto JM, Wroblewski KE, Kern DW, Schumm LP, McClintock MK. Olfactory dysfunction predicts 5-year mortality in older adults. PLoS One. 2014;9(10): e107541. https://doi.org/10.1371/journal.pone.0107541.

11. Takeda A, Baba T, Kikuchi A, Hasegawa T, Sugeno N, Konno M, et al. Olfactory dysfunction and dementia in Parkinson's disease. J Parkinsons Dis. 2014;4(2):181-7. https://doi.org/10.3233/JPD-130277.

12. Takae R, Hatamoto $Y$, Yasukata J, Kose $Y$, Komiyama T, Ikenaga M, et al. Physical Activity and/or High Protein Intake Maintains Fat-Free Mass in
Older People with Mild Disability; the Fukuoka Island City Study: A CrossSectional Study. Nutrients. 2019;11:11.

13. Takae R, Hatamoto Y, Yasukata J, Kose Y, Komiyama T, Ikenaga M, et al. Association of Lower-Extremity Muscle Performance and Physical Activity Level and intensity in middle-aged and older adults: a doubly labeled water and accelerometer study. J Nutr Health Aging. 2020;24(9):1023-30. https:// doi.org/10.1007/s12603-020-1514-1.

14. Kobayashi M, Saito S, Kobayakawa T, Deguchi Y, Costanzo RM. Cross-cultural comparison of data using the odor stick identification test for Japanese (OSITJ). Chem Senses. 2006;31(4):335-42. https://doi.org/10.1093/chemse/bjj037.

15. Saito S, Ayabe-Kanamura S, Takashima Y, Gotow N, Naito N, Nozawa T, et al. Development of a smell identification test using a novel stick-type odor presentation kit. Chem Senses. 2006;31(4):379-91. https://doi.org/10.1093/ chemse/bjj042.

16. lijima M, Kobayakawa T, Saito S, Osawa M, Tsutsumi Y, Hashimoto S, et al. Smell identification in Japanese Parkinson's disease patients: using the odor stick identification test for Japanese subjects. Internal Med (Tokyo, Japan). 2008;47(21):1887-92

17. Hirata $Y$, Matsuda $H$, Nemoto $K$, Ohnishi T, Hirao K, Yamashita F, et al. Voxelbased morphometry to discriminate early Alzheimer's disease from controls. Neurosci Lett. 2005;382(3):269-74. https://doi.org/10.1016/j.neulet.2005.03.038.

18. Matsuda H, Mizumura S, Nemoto K, Yamashita F, Imabayashi E, Sato N, et al. Automatic voxel-based morphometry of structural MRI by SPM8 plus diffeomorphic anatomic registration through exponentiated lie algebra improves the diagnosis of probable Alzheimer disease. AJNR Am J Neuroradiol. 2012;33(6):1109-14. https://doi.org/10.3174/ajnr.A2935.

19. Inoue $M$, Jinbo D, Nakamura $Y$, Taniguchi M, Urakami K. Development and evaluation of a computerized test battery for Alzheimer's disease screening in community-based settings. Am J Alzheimers Dis Other Dement. 2009; 24(2):129-35. https://doi.org/10.1177/1533317508330222.

20. Reitan RM. The relation of the trail making test to organic brain damage. J Consult Psychol. 1955;19(5):393-4. https://doi.org/10.1037/h0044509.

21. Kimura M, Mizuta C, Yamada Y, Okayama Y, Nakamura E. Constructing an index of physical fitness age for Japanese elderly based on 7-year longitudinal data: sex differences in estimated physical fitness age. Age (Dordr). 2012;34(1):203-14. https://doi.org/10.1007/s11357-011-9225-5.

22. Yesavage JA. Geriatric depression scale. Psychopharmacol Bull. 1988;24(4):709-11.

23. Palmquist E, Larsson M, Olofsson JK, Seubert J, Backman L, Laukka EJ. A prospective study on risk factors for olfactory dysfunction in aging. J Gerontol Ser A-Biol Sci Med Sci. 2020;75(3):603-10. https:/doi.org/10.1093/gerona/glz265.

24. Swan GE, Carmelli D. Impaired olfaction predicts cognitive decline in nondemented older adults. Neuroepidemiology. 2002;21(2):58-67. https:// doi.org/10.1159/000048618.

25. Wilson RS, Arnold SE, Tang Y, Bennett DA. Odor identification and decline in different cognitive domains in old age. Neuroepidemiology. 2006;26(2):61-7. https://doi.org/10.1159/000090250.

26. Wattendorf E, Welge-Lüssen A, Fiedler K, Bilecen D, Wolfensberger M, Fuhr P, et al. Olfactory impairment predicts brain atrophy in Parkinson's disease. J Neurosci. 2009;29(49):15410-3. https://doi.org/10.1523/JNEUROSCl.1909-09.2009.

27. Kashibayashi T, Takahashi R, Fujita J, Kamimura N, Okutani F, Kazui H. Correlation between regional brain volume and olfactory function in very mild amnestic patients. J Neurol Sci. 2020;411:116686. https://doi.org/10.1016/j.jns.2020.116686.

28. Bohnen NI, Müller ML, Kotagal V, Koeppe RA, Kilbourn MA, Albin RL, et al. Olfactory dysfunction, central cholinergic integrity and cognitive impairment in Parkinson's disease. Brain J Neurol. 2010;133(Pt 6):1747-54. https://doi.org/10.1093/brain/awq079.

29. Hagemeier J, Woodward MR, Rafique UA, Amrutkar CV, Bergsland N, Dwyer MG, et al. Odor identification deficit in mild cognitive impairment and Alzheimer's disease is associated with hippocampal and deep gray matter atrophy. Psychiatry Res Neuroimaging. 2016;255:87-93. https://doi.org/10.1 016/j.pscychresns.2016.08.003.

30. Shiga H, Yamamoto J, Kitamura M, Nakagawa H, Matsubasa T, Seo A, et al. Combinations of two odorants of smell identification test for screening of olfactory impairment. Auris Nasus Larynx. 2014;41(6):523-7. https://doi.org/1 0.1016/j.anl.2014.08.011.

31. Koskinen S, Kalviainen N, Tuorila H. Perception of chemosensory stimuli and related responses to flavored yogurts in the young and elderly. Food Qual Prefer. 2003;14(8):623-35. https://doi.org/10.1016/S0950-3293(02)00187-8.

32. Murphy C, Schubert CR, Cruickshanks KJ, Klein BEK, Klein R, Nondahl DM. Prevalence of olfactory impairment in older adults. Jama-J Am Med Assoc. 2002;288(18):2307-12. https://doi.org/10.1001/jama.288.18.2307. 
33. Koskinen $\mathrm{S}$, Tuorila H. Performance on an odor detection and identification test as a predictor of ortho- and retronasal odor intensity ratings in the young and elderly. Food Qual Prefer. 2005;16(5):383-92. https://doi.org/10.1 016/j.foodqual.2004.10.006

34. Duffy VB, Cain WS, Ferris AM. Measurement of sensitivity to olfactory flavor: application in a study of aging and dentures. Chem Senses. 1999;24(6):671-7. https://doi.org/10.1093/chemse/24.6.671.

\section{Publisher's Note}

Springer Nature remains neutral with regard to jurisdictional claims in published maps and institutional affiliations.

Ready to submit your research? Choose BMC and benefit from:

- fast, convenient online submission

- thorough peer review by experienced researchers in your field

- rapid publication on acceptance

- support for research data, including large and complex data types

- gold Open Access which fosters wider collaboration and increased citations

- maximum visibility for your research: over $100 \mathrm{M}$ website views per year

At $\mathrm{BMC}$, research is always in progress.

Learn more biomedcentral.com/submissions 